young and older children. During 1990-6 sensitisation $(\geqslant 3+$, wheal diameter approximately $3 \mathrm{~mm}$ ) to peanut was found in 1601 infants and children, and sensitisation to a tree nut (almond, brazil, cashew, hazelnut, or walnut) in 590; 491 were sensitised to both (fig 1). This represents a combined prevalence of sensitisation of at least $0.2 \%$. Sensitisation occurred early: 920 children aged under 24 months were sensitised to peanut and 270 to a tree nut.

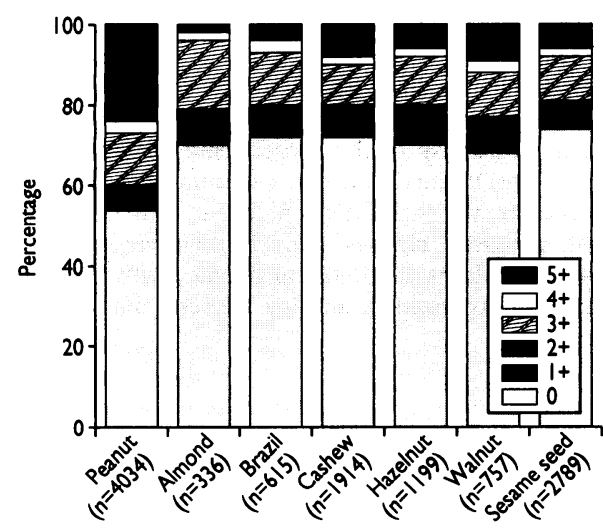

Fig 1-Maximum recorded sensitisation score for each child tested, 1990-6 $(n=4078)$. Sensitisation to nut extracts (Hollister-Stier, USA) was scored by comparing diameter of skin wheal in reaction to extract with that of wheal in reaction to histamine $1 \mathrm{mg} / \mathrm{ml}$ (on average $3 \mathrm{~mm}$ ): $1+$ if less than half diameter of histamine wheal, $2+$ if equal to half diameter, $3+$ if equal to diameter, 4+ if equal to twice diameter, and 5+ if greater than twice diameter

While skin sensitisation to allergens does not always correlate with clinical problems, we have found a strong association with increasing levels of sensitisation to specific foods. ${ }^{3}$ Open challenge of 75 children with peanut butter gave an immediate (within 30 minutes) reaction in $85 \%$ of those with a skin test result of $\geqslant 4+$. Conversely, only $13 \%$ of children with minor $(\leqslant 2+)$ evidence of sensitisation reacted on formal challenge.

We have also seen an increase in infantile eczema and anaphylaxis to food associated with sensitisation to sesame seed (fig 1). The number of children sensitised to sesame seed (531) was higher than the number sensitised to any one tree nut. Altogether 294 children were sensitised to both sesame seed and a tree nut, while 448 were sensitised to both sesame seed and peanut. Sesame seed is becoming common in the diet of this community and is found in tahini (ground sesame seed), dips, vegetable burgers, and muesli bars. ${ }^{4}$ Sensitisation also occurred early, being found in 317 children $(60 \%)$ aged under 24 months. This was illustrated by an 11 month old infant who developed facial oedema, generalised urticaria, and wheeze when given his first taste of tahini, which his mother had consumed during pregnancy and lactation.

Our previous studies have shown that multiple sensitisation to food allergens is common, especially in infants and young children undergoing expansion of their diets. ${ }^{5}$ The public health issue is not only the need for mandatory food labelling but also the need for paediatricians, trained in allergy, to evaluate infants and children who have adverse reactions.

R SPORIK Senior research fellow D HILI Director

Department of Allergy,

Royal Children's Hospital,

Melbourne, Victoria,

Melbourne, Victralia 3052

1 Ewan PW. Clinical study of peanut and nut allergy in 62 consecutive patients: new features and associations. $B M F$ secutive patients: new features
1996;312:1074-8. (27 April.)
2 Sampson H. Managing peanut allergy. BMF 1996;312:1050-1. (27 April.)

Hill DJ, Duke A, Hosking CS, Hudson IL. Clinical manifestations of cow's milk allergy in childhood. II. The diagnostic value of skin tests and RAST. Clin Allergy 1988;38:481-90. Kagi M, Wuthrich B. Falafel-burger anaphylaxis due to sesame seed allergy. Lancet 1991;338:582.

5 Bishop JM, Hill DJ, Hosking CS. Natural history of cow milk allergy clinical outcome. $\mathcal{Y}$ Pediatr 1990;116:862-7.

\section{Peanut allergy}

\section{Study's results were predictable}

EdTTOR,-J O'B Hourihane and colleagues believe that they have provided evidence for an increase in the prevalence of peanut allergy among successive generations. ${ }^{1}$ All three pieces of evidence for this proposition are, however, entirely predictable and provide no evidence in either direction.

Firstly, the authors report an increase in peanut allergy among successive generations of relatives of probands with this condition. The inheritance of peanut allergy is clearly complex, but a reduction in prevalence with successive degrees of relatives is hardly surprising. The difference in prevalence between parents and siblings can be explained by inferring the need for a genetic contribution from both parents. Had the authors shown a higher prevalence among first cousins than among parents their assertion would be more plausible.

Secondly, consumption of peanuts was found to be higher among mothers of probands aged 5 and under than among mothers of probands older than 5 . Half of the group of probands older than 5 were aged over 16 . Consumption of peanuts has increased over that time. It is thus inevitable that the mothers of any group of young children will have consumed more peanuts during pregnancy than a comparable group of older children and adults.

The authors further report that the age at onset of peanut allergy was inversely correlated with year of birth. This is again inevitable for any condition that can occur throughout life. A subject can have developed a condition only at an age less than his or her current age; thus a population of older people with any such condition, be it diabetes, epilepsy, or allergy, will include subjects who developed the condition later than those in a younger population. If the authors statistically corrected for this phenomenon they do not mention it.

ROLLO CLIFFORD

Department of Paediatrics, West Dorset Hospital, Dorchester DT1 2JY

1 Hourihane JO'B, Dean TP, Warner JO. Peanut allergy in relation to heredity, maternal diet, and other atopic diseases: results of a questionnaire survey, skin prick testing, and food challenges. BMf 1996;313:518-21. (31 August.)

\section{Authors' reply}

EdrToR,-Rollo Clifford comments that the prevalence of peanut allergy in the siblings of subjects with peanut allergy is unsurprising, considering the rates of parental atopy. Our conclusion simply stated that this "probably reflects similar early exposure of offspring of atopic parents to peanuts." Information about cousins would have been unreliable compared with that about the presenting family. The rate of proved peanut allergy in the siblings of our subjects $(3 / 39(8 \%))$ is significantly higher than that in the general population ${ }^{1}(6 / 981(0.6 \%)$ children aged 4 living on the Isle of Wight) $\left(\chi^{2}=5.14\right.$, $\mathrm{P}=0.0002$, odds ratio 13.54 ( $95 \%$ confidence interval 3.52 to 56.31 )) and is also significantly higher than that shown in Zeiger et al's study of
2 year olds at high risk of atopy. ${ }^{2}$ Out of 288 infants whom Zeiger et al studied, three were shown to have peanut allergy $\left(\chi^{2}=5.14\right.$, $\mathrm{P}=0.023$, odds ratio 7.91 (1.54 to 40.7$)$ ). Being the sibling of someone with peanut allergy confers a higher risk of peanut allergy than simply coming from a non-specifically high risk family.

With regard to Clifford's second point, we agree that there has been an inevitable increase in consumption of peanuts by mothers of young children (not just mothers of children with peanut allergy). We are suggesting that an association may exist between this and the decreasing age at onset of peanut allergy.

Comparison of peanut allergy with diabetes is not valid. Diabetes often starts in adolescence and adulthood, whereas peanut allergy starts almost universally in childhood. Altogether 73\% of our subjects, both children and adults, reacted to their first exposure to peanuts. Clifford is right to say that everyone reports onset of illness at an age younger than their current age. $\mathrm{He}$ has missed the more relevant point that there is no statistical or sampling reason why older subjects should not have developed peanut allergy in the first years of life. The lower left quadrant of our graph is empty of subjects because of the biological reason that older subjects were not exposed to peanuts at a young age and did not develop peanut allergy until they were so exposed. Our finding is supported by reanalysis with Lowess regression smoothing that uses iterative locally weighted sampling of least squares.

Our research confirms many suspicions of doctors and health workers regarding the increasing prevalence of peanut allergy and its major impact on young members of atopic families.

JONATHAN O'B HOURIHANE Clinical research fellow $J$ O WARNER Professor $T$ P DEAN
Senior research fellow

Child Health,

University of Southampton,

Southampton General Hospital,

Southampton SO16 6YD

1 Tariq SM, Stevens M, Matthews S, Ridout S, Twiselton R, Hide DW. Cohort study of peanut and tree nut sensitisation by age of 4 years. BMf 1996;313:514-7. (31 August.)

2 Zeiger RS, Heller MSN, Mellon MH, Forsythe AB, O'Connor $\mathrm{RD}$, Hamburger RN, et al. Effect of combined maternal and infant food-allergen avoidance on development of atopy in early infancy: a randomised study. $f$ Allergy Clin Immunol early infancy: a
1989;84:72-89.

\section{Should breast reduction surgery be rationed?}

\section{Only a third of women studied completed both questionnaires}

EDITOR,-Anne Klassen and colleagues conclude from their study that breast reduction surgery improves the health status of women and should be included in NHS purchasing contracts. ${ }^{1}$ We are concerned, however, about the high number of patients excluded from the crucial analysis.

Of 166 patients deemed to be studied, only $128(77 \%)$ responded to the preoperative questionnaire. Why 10 of the 166 patients were excluded is not clear. The response rate to the postoperative questionnaire was even worse: of the 128 patients who responded to the preoperative questionnaire, only 85 were operated on and only $58(68 \%)$ completed the postoperative questionnaire. Finally, only 54 women (that is, $33 \%$ of the initial 166) completed both the preoperative and the postoperative questionnaires; this is the most important group of patients. Although there was no significant difference in most variables between non- 
responders and responders, the statistical power of this analysis was low, and the authors' main conclusion is based on the responses of only 54 patients. We wonder how many of the 31 non-responders would have had to be unsatisfied with the operation to reverse the results of the statistical analysis. We suspect that it would not be many.

JAYANT $S$ VAIDYA Research fellow NIGEL SACKS

Consultant surgeon

Academic Department of Surgery,

Royal Marsden Hospital,

London SW3 6JJ

1 Klassen A, Fitzpatrick R, Jenkinson C, Goodacre T. Should breast reduction surgery be rationed? A comparison of the health status of patients before and after treatment; posta questionnaire survey. BMF 1996;313:454-7. (24 August.)

\section{Interventions requested for psychological} reasons should be studied

EDrToR,-We were interested to note that Anne Klassen and colleagues chose to look at breast reduction as an example of a cosmetic surgery procedure that is not being provided by the NHS. ${ }^{1}$ They comment that common reasons for referral were physical problems (for example, pain, discomfort, and skin irritation); psychological and social reasons were less common. They conclude that breast reduction is an effective treatment for these women. We question the relevance of this study to the debate on rationing, and particularly whether the findings can be taken to indicate the benefits likely to come from other cosmetic surgery procedures.

South and West Devon Health Authority has operated a policy of restricted access to certain cosmetic surgery procedures, including breast reduction, for over a year. Under this policy requests for breast reduction because of physical symptoms have invariably been approved; such requests constitute a small proportion of the requests for cosmetic surgery (table 1 ).

Table 1 - Proportion of requests for breast surgery accepted by South and West
1 January to 30 June 1996

\begin{tabular}{lcc}
\hline Procedure & $\begin{array}{c}\text { No of } \\
\text { requests }\end{array}$ & $\begin{array}{c}\text { No (\%) } \\
\text { accepted }\end{array}$
\end{tabular}

Breast reduction:

\section{Physical symptoms}

Psychological symptoms

Other cosmetic surgery*

Total

10

84

$118 \quad 79(67)$

Including, for example, breast augmentation, removal of cysts and tattoos, rhinoplasty, and apronectomy.

Of greater relevance to the rationing debate is the effectiveness of other procedures, such as breast augmentation, when the reasons for referral are psychological. We hope that future studies will address the issue of effective interventions, including non-surgical management, for such psychological need.

MARGARET SOMERVILIE Consultant, public health department GINA RADFORD

Team leader, incident room NICOLA HEWS Information office

South and West Devon Health Authority,

Dartington TQ9 6JE

1 Klassen A, Fitzpatrick R, Jenkinson C, Goodacre T. Should breast reduction surgery be rationed? A comparison of the health status of patients before and after treatment: postal questionnaire survey. BMF 1996;313:454-7. (24 August.)

\section{Authors' reply}

EDITOR,-We share Jayant $S$ Vaidya and Nigel Sacks's concern about the response rate in our study. Space did not allow us to report the reasons for 10 patients being excluded from the preoperative assessment. Three respondents had the operation done privately; the questionnaires of two respondents were returned by the post office because they had moved; two respondents had their operation before completing the preoperative questionnaire; the solicitor of one patient asked that she be removed from the survey because of a legal case pending against the hospital; one respondent proved to be under the minimum age for entry to the study; and one respondent decided that she no longer wanted surgery.

To assess further any possible biases in the results produced by non-response we have performed logistic regression, with whether patients responded to the follow up questionnaire as dependent variable and using a model of all the available health status data from the baseline assessment and demographic and waiting time variables. The model did not fit the data, which suggests that there was no obvious overall bias in terms of follow up. Furthermore, even if every woman who failed to respond to the follow up survey was dissatisfied with the result of her surgery (an implausible assumption), overall $68 \%(50 / 74)$ would have regarded the outcome as excellent or good.

We agree with Margaret Somerville and colleagues that caution is needed in generalising from breast reduction to other forms of cosmetic surgery. Patients awaiting breast reduction surgery represented a quarter of referrals to plastic surgeons for possible cosmetic procedures in Oxford region in 1993. In an assessment of 198 patients having a wider range of cosmetic surgical procedures those who had breast reduction surgery had the worst scores on the physical and pain dimensions of the short form 36 before surgery and, six months postoperatively, showed the most benefit in terms of effect sizes for these dimensions. ${ }^{1}$ They also experienced the greatest improvement in psychological wellbeing as reflected by the 28 item general health questionnaire.

RAY FITZPATRICK Professor ANNE KLASSEN Research officer CRISPIN JENKINSON Deputy director, health services research unit Department of Public Health and Primary Care, University of Oxford,

Radcliffe Infirmary, Oxford OX2 6HE

TIM GOODACRE Consultant plastic surgeon Department of Plastic and Reconstructive Surgery, Radcliffe Infirmary

1 Klassen A, Jenkinson C, Fitzpatrick R, Goodacre T. Patients' health related quality of life before and after aesthetic surgery. Br $\mathcal{F}$ Plast Surg 1996;49:433-8.

\section{Fatal methadone overdose}

\section{Better understanding of body's handling of} methadone is needed

EDITOR,- T J Hendra and colleagues describe a case in which postmortem concentrations of methadone were substantially higher than those in a sample of blood taken, by our calculations, about 28 hours before death. ${ }^{1}$ They speculate that this indicates either delayed absorption from the gut or surreptitious consumption of methadone after admission to hospital. We suggest that the liver might have had a role.

Experimental studies show that the liver avidly extracts methadone from blood, stores some of it unchanged, and can release it back into the effer- ent bloodstream. ${ }^{2}$ Handling of methadone is altered in chronic liver disease, ${ }^{3}$ and methadone itself may be hepatotoxic. ${ }^{4}$ We have found it impossible to guess what effect these three phenomena might have in concert, but we suspect that, given the correct stimulus, the liver might be capable of releasing substantial amounts of methadone into the bloodstream long after ingestion. Perhaps that stimulus might be the improvement in the patient's general condition engendered by intensive care.

A further factor that confounds interpretation is the observation that blood methadone concentrations at different sites at necropsy may differ by a factor of over three in a single subject and that no systematic relation exists between the concentrations at different sites. ${ }^{5}$ In addition, methadone is likely to be released by autolysis from those cells that concentrated it during life. ${ }^{2}$ It is thus difficult to interpret blood methadone concentrations at necropsy and to be sure that there was more methadone in the circulation in Hendra and colleagues' patient at death than in the sample of blood taken on the day of admission. Better understanding of the body's handling of methadone is needed.

EMYR W BENBOW Senior lecturer in pathology IAN S D ROBERTS Lecturer in pathology

University of Manchester Manchester M13 9P1

ALISON CAIRNS

Leeds General infirmary, Registrar in pathology

Leeds LS1 3EX

Hendra TJ, Gerrish SP, Forrest ACW. Fatal methadone overdose. $B M \Im$ 1996;313:481-2. (24 August.)

Kreek MJ, Oratz M, Rothschild MA. Hepatic extraction of long- and short acting narcotics in the isolated perfused rabbit liver. Gastroenterology 1978;75:88-94.

3 Novick DM, Kreek MJ, Fanizza AM, Yankovitz SR, Gelb AM, Stenger RJ. Methadone disposition in patients with chronic liver disease. Clin Pharmacol Ther 1981;30:353-62.

4 Jover R, Ponsoda X, Gomez-Lechon MJ, Castell JV. Potentiation of heroin and methadone hepatotoxicity by ethanol: in vitro study using cultured human hepatocytes. Xenobiotica 1992;22:471-8.

5 Levine B, Wu SC, Dixon A, Smialek JE. Site dependence of postmortem blood methadone concentrations. Am $\mathcal{f}$ Foren sic Med Pathol 1995;16:97-100.

Naloxone infusion should have been started earlier

EDIToR,-We wish to make several points about the case of fatal methadone overdose reported by T J Hendra and colleagues. ${ }^{1}$ The initial management of the patient causes us particular concern Flumazenil was relatively contraindicated in the patient because he was known to have epilepsy and there was a high probability of a mixed overdose, given his access to other drugs and his history; such patients are commonly dependent on benzodiazepines. ${ }^{2}{ }^{3}$

In opiate poisoning an initial bolus of $0.8-2 \mathrm{mg}$ of naloxone is recommended; this should be repeated to a maximum of $10 \mathrm{mg}$ before other drugs causing depression of the central nervous system are considered. ${ }^{4}$ The naloxone infusion should have been started earlier, given the extended half life of methadone; the use of occasional boluses is hazardous. Once the infusion was started the rate of infusion remained inadequate, with supplemental boluses being required.

After transfer to the general ward the patient died at some point a few hours after the naloxone infusion stopped. The comment that "the naloxone infusion was slow to complete, eventually finishing at 0330 " is unfortunate, implying that a course of treatment had been concluded after a notional timescale, without reference to the patient's clinical status. Given the short half life of naloxone, the danger period could have been predicted to occur in the few hours after the 